\title{
Finite Element Analysis of the Geogrid-Pile Foundation System under Earthquake Loading
}

\author{
Athraa A. Al-Ghanim¹, Qassun S. Mohammed Shafiqu², Asma Thamir Ibraheem³
}

\section{$\underline{\text { Authors affiliations }}$ \\ (1) Civil Eng. Dep. Al-Nahrain \\ University, Baghdad, Iraq. athraaabdulameersadiq@gmail.com}

(2) Civil Eng. Dep. Al-Nahrain University, Baghdad, Iraq. qassun.almohammed@eng.nahrain univ.edu.iq

(3) Civil Eng. Dep. Al-Nahrain University, Baghdad, Iraq. drasma2005@eng.nahrainuniv.edu. iq

\section{Paper History:}

Received: $7^{\text {th }}$ May 2019

Revised: $7^{\text {th }}$ June 2019

Accepted: $17^{\text {th }}$ Sep. 2019

\begin{abstract}
The finite element method is one of the important methods in analyzing geotechnical engineering problems; its main advantage is the ability to apply for the materials exhibiting non-linear stressstrain behavior. In this study the finite element program PLAXIS 3D 2013 is used to study the behavior of the piles under the influence of seismic waves in saturated sandy soil and the effect of adding geogrid with the pile foundation. The program has been used to facilitate the representation of the real model, input the required soil parameters and implementation of seismic data. Seismic wave, the soil geometry and the pile dimensions were fixed in all models, while dimension and depth of the geogrid used were varied to study the influence of different depth and dimension in reducing the pile displacements and the pore water pressure of soil. The results show that The reduction in settlement ratio (the difference between settlement of pile without and with using geogrid to the settlement without using geogrid) for $(\mathrm{L} / 2 \times \mathrm{L} / 2)$, $(\mathrm{L} \times \mathrm{L})$ and $(2 \mathrm{~L} \times 2 \mathrm{~L})$ are $10.6 \%, 17 \%$ and $21.3 \%$ respectively. And the settlement ratio for geogrid at depths $8.33 \%$ and $12.5 \%$ of pile length are $9.6 \%$ and $17 \%$ respectively
\end{abstract}

Keywords: Finite Element Analysis, Pile, Geogrid, Loose Sand, Earthquake, Mohr-Columb Model.

\section{Introduction}

Increasing seismic activity in Iraq areas lead researchers to investigate the effect of dynamic effects on the behavior of pile foundations in sandy soils like Al-Recaby [3], Al-Tameemi [4], Salem [8] \& Sa'ur [9]. Some of these researches highlighted the behavior of pile under real earthquakes like Al-Tameemi [4] \& Sa'ur [9] that used Halabjah and Ali Al Gharbi earthquake respectively. Previous researches confirmed that the soil improvement reduces the damage of foundations and structures thus the geogrids were used to improve the soil (Fakhraldin [6] \& Taha [10]). Different researches likes Abdulrasool [1], Al-Recaby [3], Salem [8] \& Sa'ur [9] used PLAXIS $3 \mathrm{D}$ in dynamic analysis of foundation which provide good results when simulating the real models, so that it is used in this study. And because of rare information about using geogrid with pile foundation under the real earthquakes in sandy soils, this research has been carried out. The investigations were carried out on pile foundation model, which subjected to Halabjah earthquake, with acceleration equal to $0.1 \mathrm{~g}$.

\section{The Geometry Model of Pile-Geogrid System}

The model used in the current study is single pile $0.8 \mathrm{~m}$ in diameter and $7.5 \mathrm{~m}$ depth embedded in saturated sandy soil performed by Al-Tameemi [4] using FLAC ${ }^{3 \mathrm{D}}$ program. The dimensions of finite element model used are $15 \times 15 \times 15 \mathrm{~m}$ long, wide and depth respectively as shown in Fig.(1). Then investigate the effect of adding different dimensions and depths of Nelton CE121 geogrid which tested by Fakhraldin [6] \& Al-Essawi [2] to study the pile settlement and pore water pressure under the effect of Halabjah earthquake. The applied load concentrated above the pile is $625 \mathrm{kN}$ as described by Al-Tameemi [4].

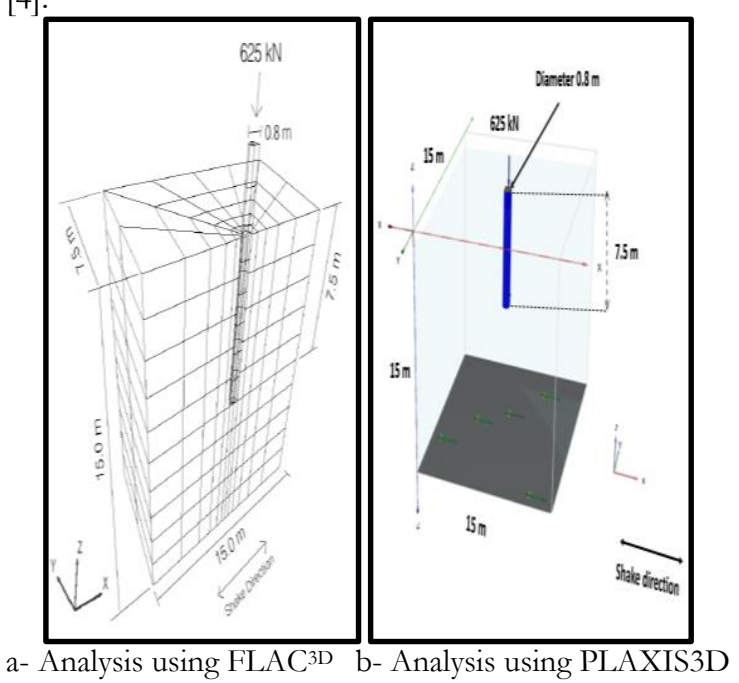

Figure (1): The geometry model

NJES is an open access Journal with ISSN 2521-9154 and eISSN 2521-9162

This work is licensed under a Creative Commons Attribution-NonCommercial 4.0 International License 


\section{The Information for Models Used}

\subsection{The Models of Soil and Pile}

The soil used is loose sandy soil with relative density 33\%; the other properties listed in Table (1). The pile used in all models is single concrete pile, its length is $7.5 \mathrm{~m}$ with a diameter $0.8 \mathrm{~m}$ (i.e., $\mathrm{L} / \mathrm{d}$ is 9.4 ) and the applied load was $625 \mathrm{kN}$ (Al-Tameemi, 4). The pile was designed as cylinder and give the properties of plate, the input properties for the soil and pile (plate properties) are listed in Table (1), the material models are Mohr Coulomb for soil and linear elastic for pile as used by Al-Recaby [3].

Table (1): Material properties for soil and pile models (after Al-Tameemi, 4)

\begin{tabular}{|c|c|c|}
\hline Parameter & Loose sand & Pile (plate) \\
\hline$\gamma_{\text {unsat. }}\left(\mathrm{kN} / \mathrm{m}^{3}\right)$ & 15.65 & 25 \\
\hline$\gamma_{\text {sat. }}\left(\mathrm{kN} / \mathrm{m}^{3}\right)$ & 18.5 & - \\
\hline $\mathrm{E}\left(\mathrm{kN} / \mathrm{m}^{2}\right)$ & $234 \times 10^{3}$ & $24.96 \times 10^{3}$ \\
\hline$\nu$ & 0.3 & 0.2 \\
\hline$\phi($ degree $)$ & 34 & - \\
\hline$\Psi($ degree $)$ & 4 & - \\
\hline $\mathrm{V}_{\mathrm{s}}(\mathrm{m} / \mathrm{s})$ & 237.4 & - \\
\hline $\mathrm{V}_{\mathrm{p}}(\mathrm{m} / \mathrm{s})$ & 444.1 & \\
\hline Raylieh $\alpha$ & 0.05 & - \\
\hline Raylieh $\beta$ & 0.2 & - \\
\hline Data set & Standard & - \\
\hline$R_{\text {interface }}$ & 0.8 & - \\
\hline
\end{tabular}

\subsection{The Geogrid Model}

The geogrid induced in PLAXIS 3D is Nelton CE121, which has stiffness equal to $221 \mathrm{kN} / \mathrm{m}, 3534$ $\mathrm{kN} / \mathrm{m}$ and $400000 \mathrm{kN} / \mathrm{m}$ for $\mathrm{L} / 2 \times \mathrm{L} / 2, \mathrm{~L} \times \mathrm{L}$ and $2 \mathrm{~L} \times 2 \mathrm{~L}$ respectively according to Meymand et al. [7], El-Emam et al. [5] \& Taha [10] as shown in Fig. (2), since they multiplied the geogrid stiffness by $\lambda^{2}$.

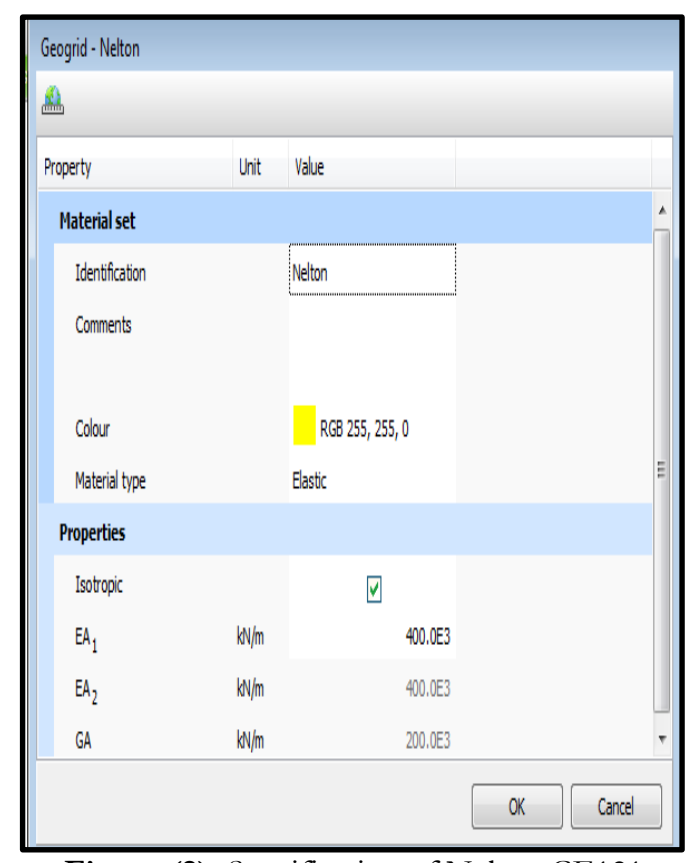

Figure (2): Specification of Nelton CE121 geogrid

\subsection{Earthquake Modeling}

The earthquake inserted into the base of the model using prescribed displacement in the X-direction as indicated by Abdulrasool [1] \& Sa'ur [9]. The earthquake information used in the current research is Halabjah earthquake, the readings of the earthquake entered as a table of time and acceleration records in (s) and (g) respectively. Acceleration-Time records of earthquake are shown in Fig. (3).

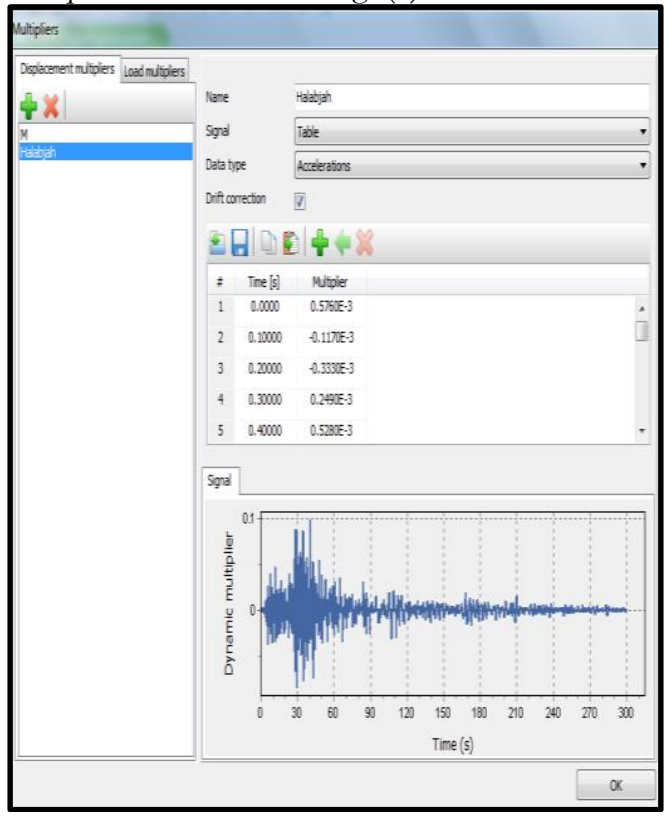

Figure (3): Acceleration-time records of Halabjah earthquake during 300 second

\section{Mesh Generation}

Figure (4) show the mesh generation of the soil, the pile and the geogrid used. The mesh consists of 10node tetrahedral element, the coarse mesh created because of the large model dimensions.

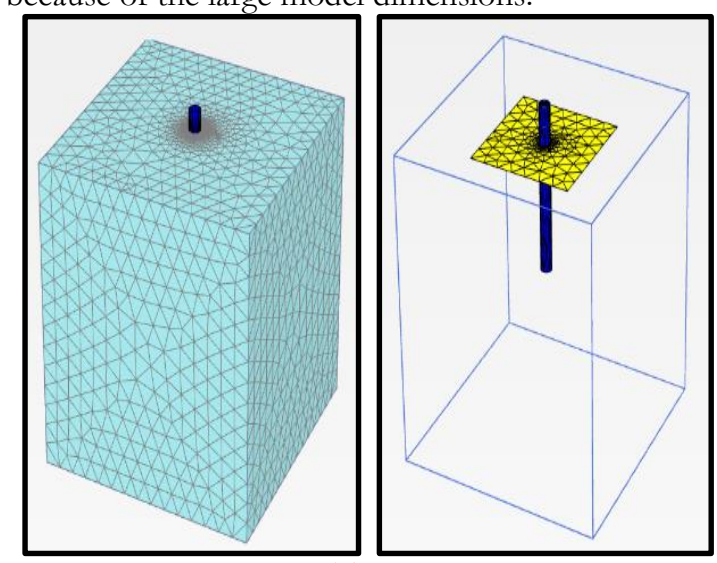

Figure (4): The mesh generation

\section{Performing Calculations}

Calculations performed by using four phases as shown in Fig. (5-a). The initial phase is generated to calculate the initial stresses of soil and the pore water pressure. The first phase calculation type used is plastic and the pressure used from the previous phase, inserted soil, pile and geogrid in the model explorer. Second phase, the pore pressure calculation type is phreatic and model explorer contain surface load in addition to that contain in the previous phase. Third 
Phase is the dynamic type, in this phase, activate the reset displacement to zero, surface displacements in model explorer and the dynamic, then choose viscous boundary condition, close the ground water flow and select four points for curves as shown in Fig. (5-b).

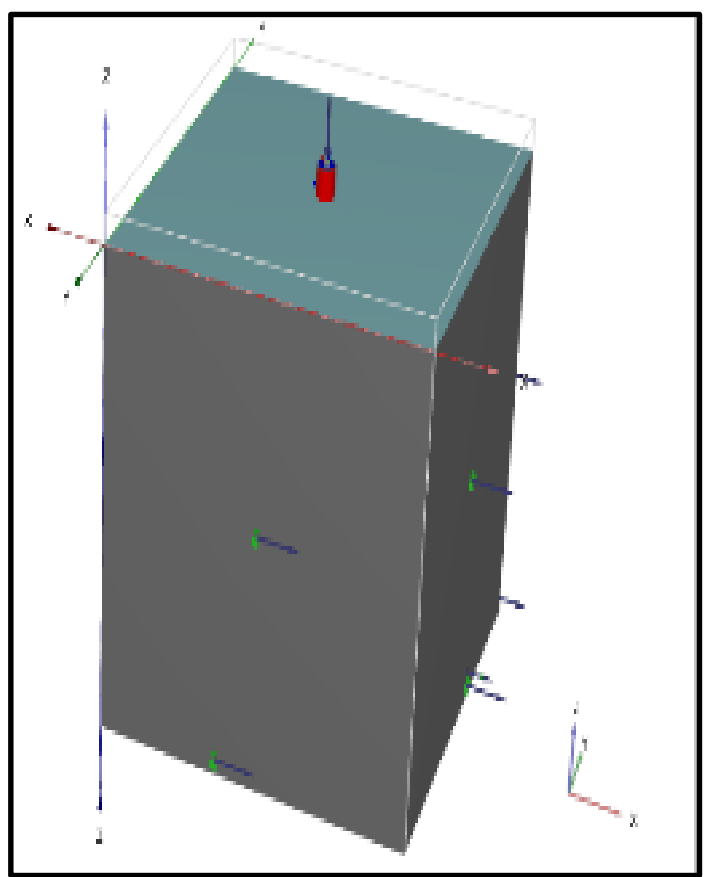

(a)

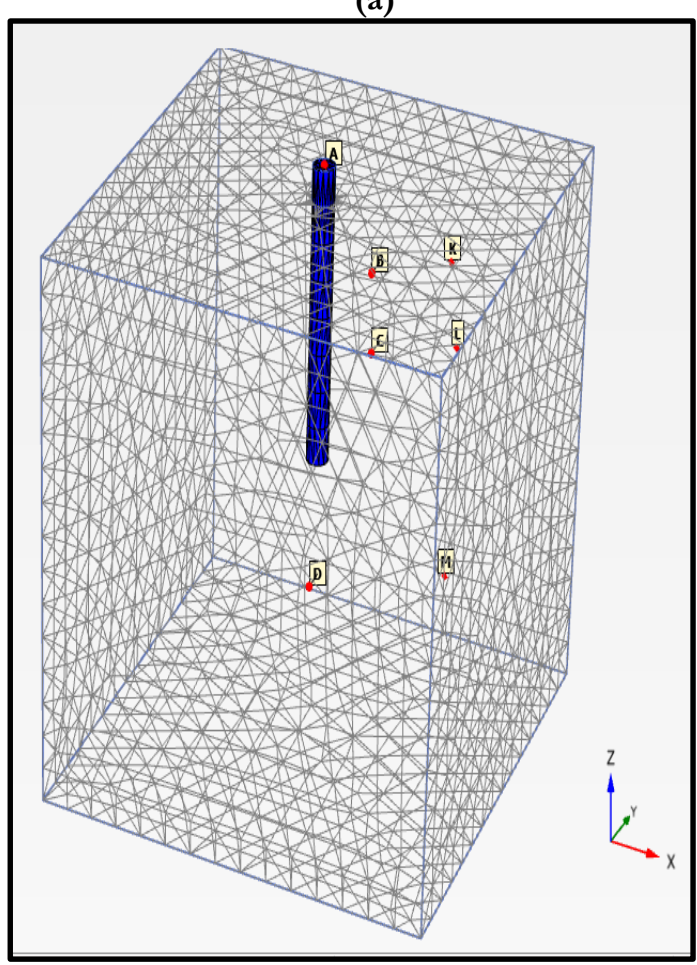

(b)

Figure (5): The staged construction

\section{Results}

\subsection{The Comparison between FLAC ${ }^{3 d}$ and PLAXIS 3D 2013}

The comparison between results obtained by FLAC ${ }^{3 D}$ and PLAXIS 3D 2013 is inserted in Table (2). The results show that the pore water pressure of the saturated soil in PLAXIS 3D is smaller than that obtained by FLAC ${ }^{3 \mathrm{D}}$, and the settlement is greater than recorded by FLAC ${ }^{3 \mathrm{D}}$, this may be due to the different in the mesh generation of the model, and then the coordinates of the points at which the results recorded vary.

Table (2): The comparison between the maximum values of pore water pressure and settlement

\begin{tabular}{|c|c|c|c|}
\hline $\begin{array}{c}\text { Earthqua } \\
\text { ke type }\end{array}$ & Parameters & FLAC 3D & $\begin{array}{c}\text { PLAX } \\
\text { IS 3D }\end{array}$ \\
\hline \multirow{4}{*}{ Halabjah } & $\mathrm{u}_{1}\left(\mathrm{kN} / \mathrm{m}^{2}\right)$ & 55 & 71 \\
\cline { 2 - 4 } & $\mathrm{u}_{2}\left(\mathrm{kN} / \mathrm{m}^{2}\right)$ & 95 & 90 \\
\cline { 2 - 4 } & $\mathrm{u}_{3}\left(\mathrm{kN} / \mathrm{m}^{2}\right)$ & 215 & 165 \\
\cline { 2 - 4 } & Settlement $(\mathrm{mm})$ & 756 & 938 \\
\hline
\end{tabular}

\subsection{Effect of Geogrid Dimensions}

The dimensions of geogrid used are $(3.75 \mathrm{~m} \times 3.75 \mathrm{~m}),(7.5 \mathrm{~m} \times 7.5 \mathrm{~m})$ and $(15 \mathrm{~m} \times 15 \mathrm{~m})$ which correspond to $\left(\frac{\mathrm{L}}{2} \times \frac{\mathrm{L}}{2}\right),(\mathrm{L} \times \mathrm{L})$ and $(2 \mathrm{~L} \times 2 \mathrm{~L})$ respectively. The results given in Fig. (6) illustrate that adding geogrid to soil will reduce the settlement and this reducing will increase as geogrid dimensions increase. The reduction in settlement ratio (the difference between settlement of pile without and with using geogrid to the settlement without using geogrid) for $\left(\frac{\mathrm{L}}{2} \times \frac{\mathrm{L}}{2}\right),(\mathrm{L} \times \mathrm{L})$ and $(2 \mathrm{~L} \times 2 \mathrm{~L})$ are $10.6 \%, 17 \%$ and $21.3 \%$ respectively. It has been found that the horizontal displacement in shaking direction are unaffected. The horizontal displacement in opposite shaking direction is reduce with reducing dimensions of geogrid. In addition, the pore water pressure in first layer decrease with small dimension and increase with large dimension which may be due to increasing in acceleration, while in lower layers the pore water pressure decreasing with increasing geogrid dimensions.

\subsection{Effect of Geogrid Depth}

Figure (7) show the comparison between the results for pile foundation reinforced with geogrid mesh of dimension $\mathrm{L} \times \mathrm{L}$ at different depths $\mathrm{L} / 12$ and $\mathrm{L} / 8$ that corresponds to $8.33 \%$ and $12.5 \%$ of pile length. The results illustrate that when geogrid spread deeper in the soil, the settlement and the horizontal displacement in the direction opposite to shaking are reduce, while the displacement in the shaking direction is unaffected, also the pore water pressure are decrease in the upper layer and increase in the lower layers due to increasing the pressure beneath the geogrid mesh. The settlement ratio for geogrid at depths $8.33 \%$ and $12.5 \%$ of pile length are $9.6 \%$ and $17 \%$ respectively. 


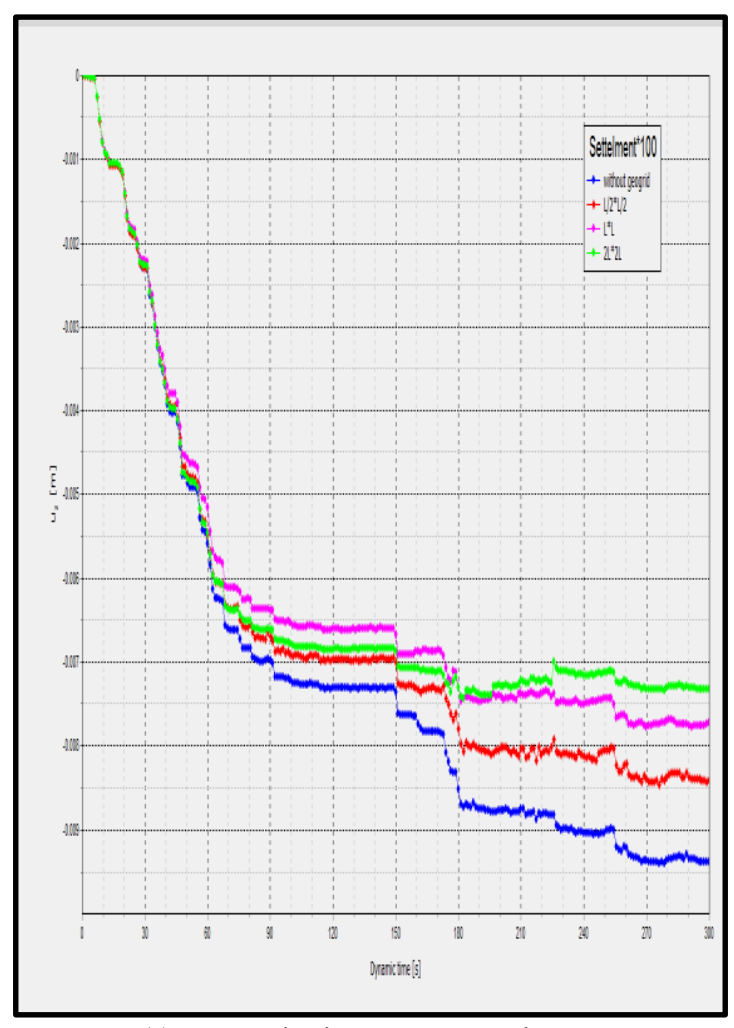

(a) Dynamic time versus settlement

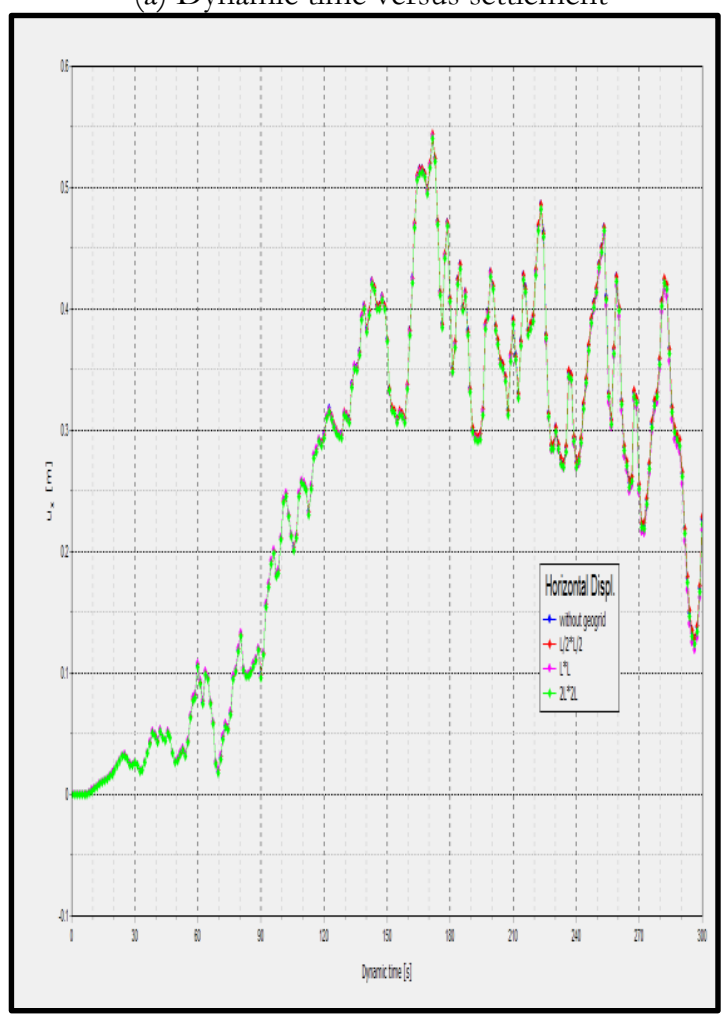

(b) Dynamic time versus horizontal displacement $\mathrm{X}$

Figure (6): The comparison between different dimensions of geogrid

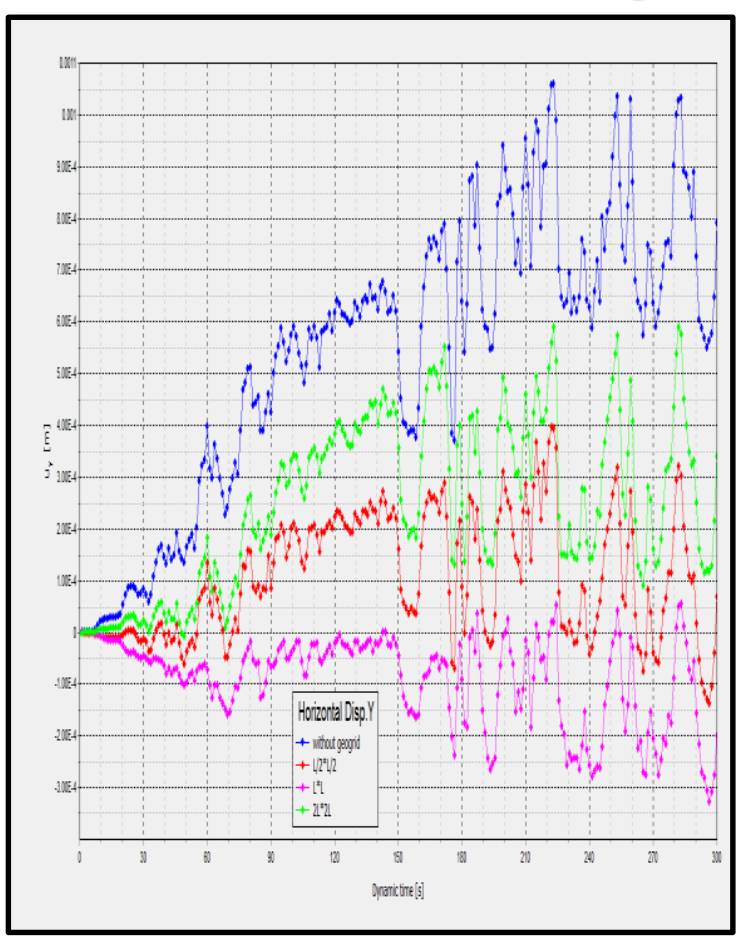

(c) Dynamic time versus horizontal displacement $\mathrm{Y}$

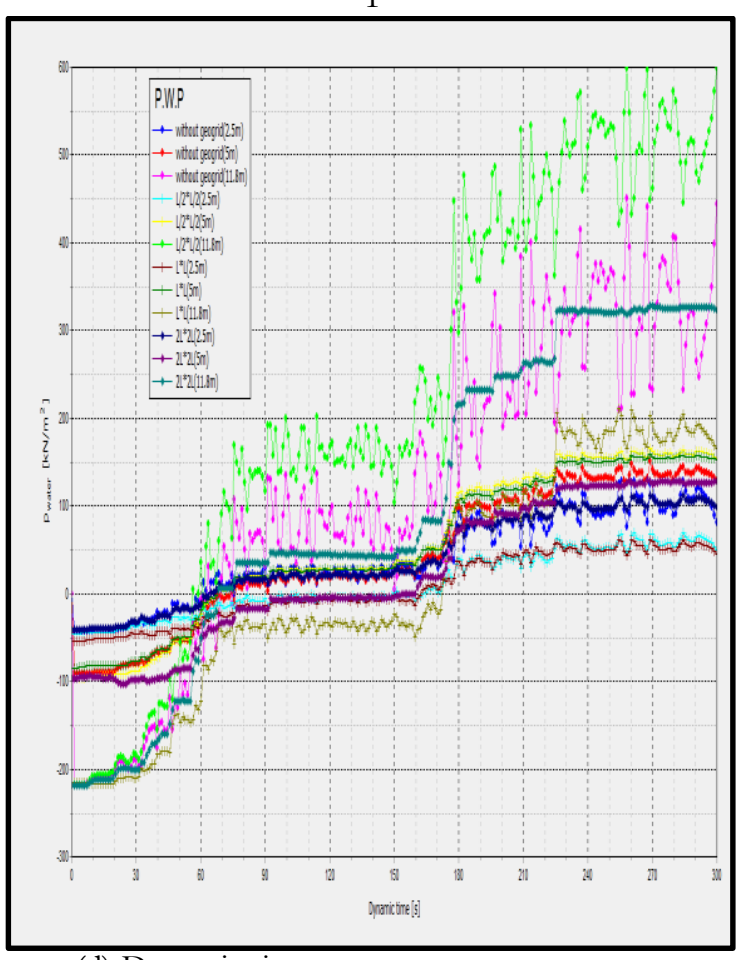

(d) Dynamic time versus pore water pressure

Figure (6): Continued 


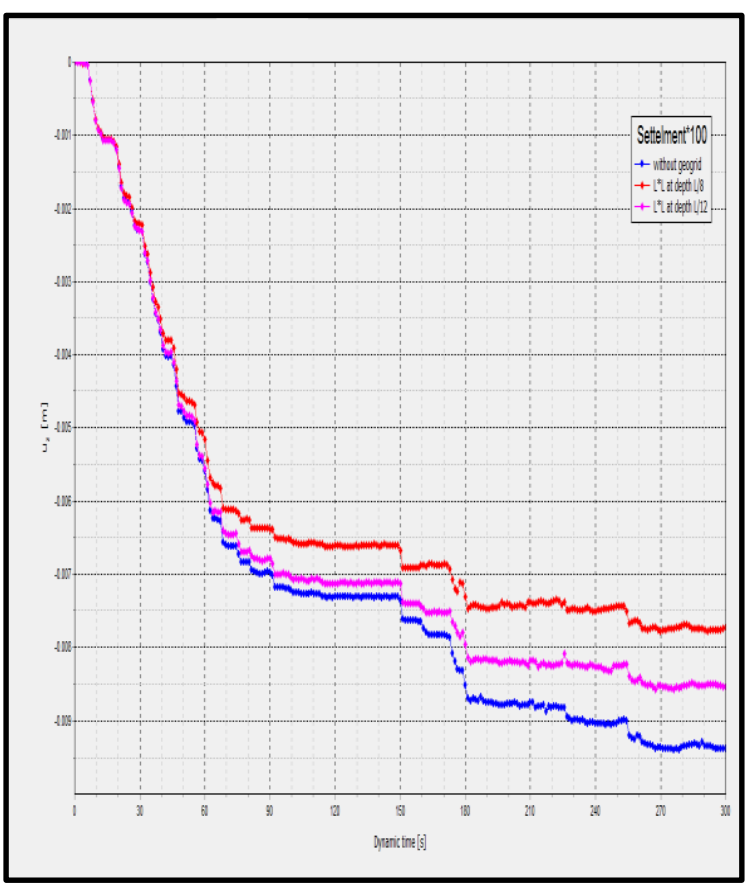

(a) Dynamic time versus settlement

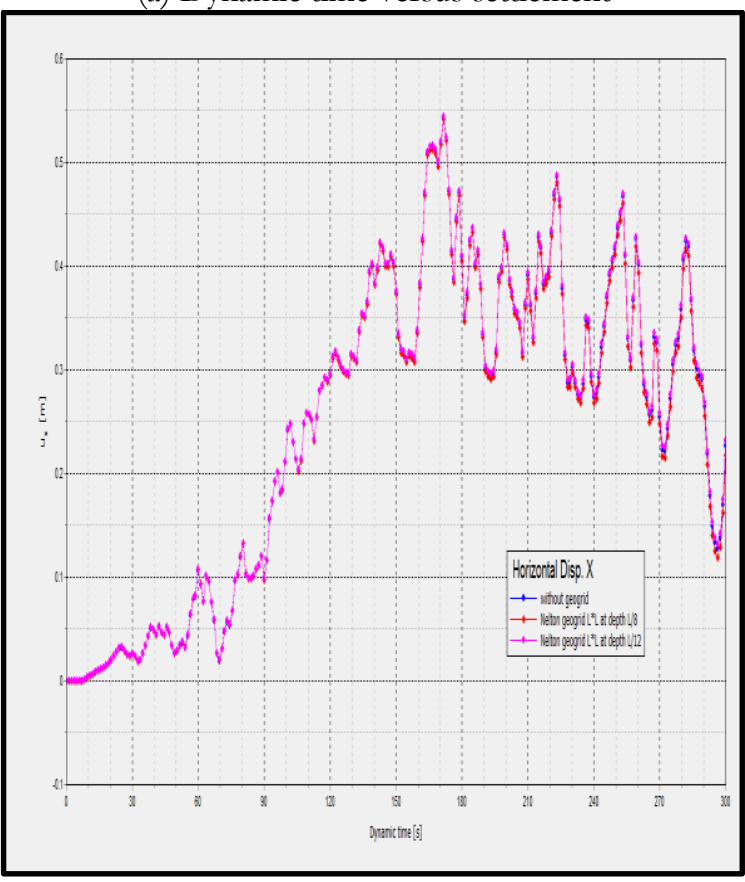

(b) Dynamic time versus horizontal displacement $\mathrm{X}$

Figure (7): The comparison between different depths of placing geogrid

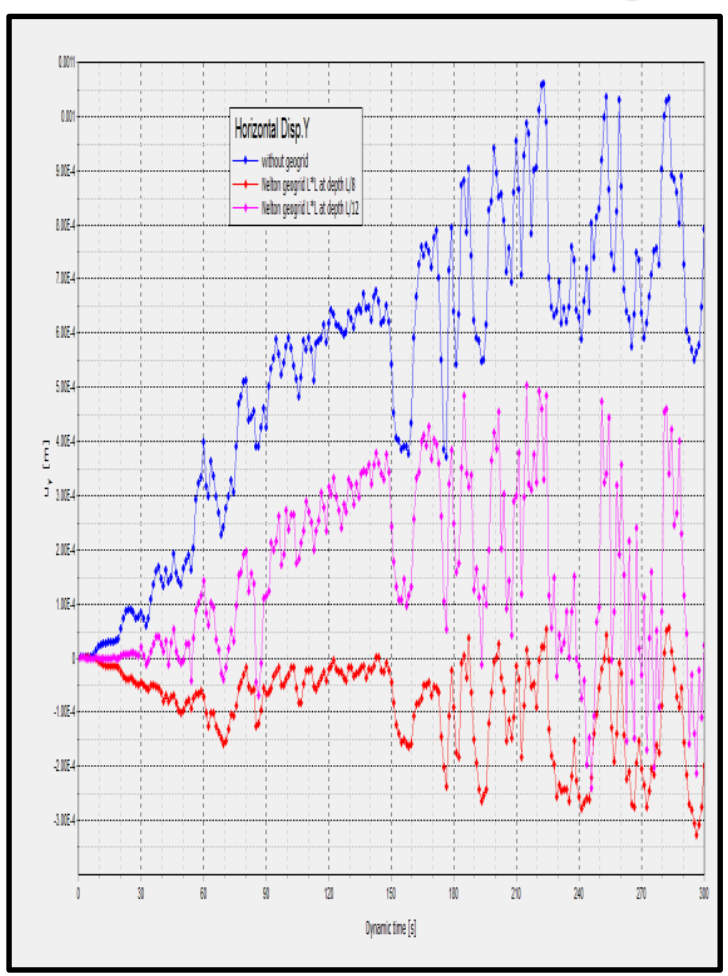

(c) Dynamic time versus horizontal displacement $\mathrm{Y}$

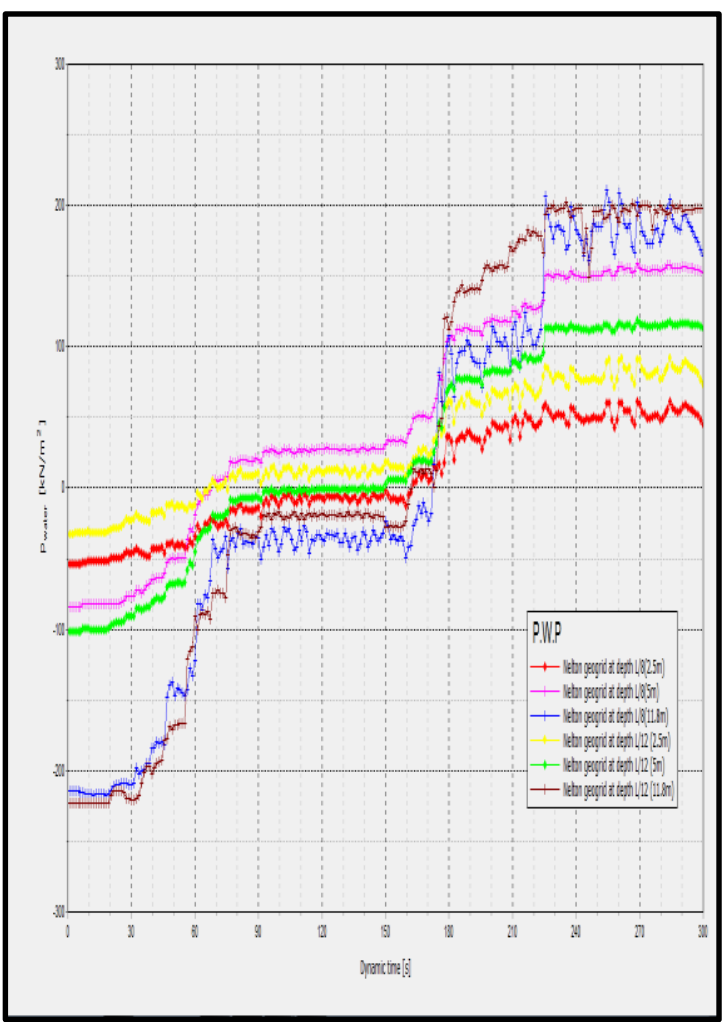

(d) Dynamic time versus pore water pressure

Figure (7): Continued

\section{Conclusions}

1. When comparing the results of FLAC ${ }^{3 \mathrm{D}}$ and PLAXIS 3D 2013. The pore water pressure of the saturated soil in PLAXIS 3D is smaller than that obtained by FLAC ${ }^{3 \mathrm{D}}$, and the settlement is greater than recorded by FLAC ${ }^{3 \mathrm{D}}$. In general, the compatibility between the results considered as good. 
2. When the dimensions of geogrid are increased $(\mathrm{L} / 2 \times \mathrm{L} / 2),(\mathrm{L} \times \mathrm{L})$ and $(2 \mathrm{~L} \times 2 \mathrm{~L})$, the settlement of the pile decrease, then increasing the settlement ratios to $10.6 \%, 17 \%$ and $21.3 \%$ respectively. Increasing the dimensions of geogrid over the length of pile leads to increase the total acceleration of the pile and increase the pore water pressure in first soil layer while decrease in the lower soil layers.

3. Putting the geogrid deeper from $8.33 \%$ to $12.5 \%$ of pile length into the soil will reduce the displacements of pile and the settlement ratio is $9.6 \%$ and $17 \%$ and the pore water pressure in the upper layer while it increases the pore water pressure in the lower layers. Since the settlement ratio for geogrid at depths $8.33 \%$ and $12.5 \%$ of pile length are $9.6 \%$ and $17 \%$ respectively

4. The horizontal displacement towards shaking direction is unaffected with placing geogrid inside the soil.

\section{References}

[1] Abdulrasool, M.A. and Qassun S. Mohammed Shafiqu (2018). "Finite Element Analysis of Raft Foundation on Various Soil Types under earthquake Loading", International Journal of Architectural, Civil and Construction Sciences ISSN: 2415-1734 Vol: 12, No: 9.

[2] Al-Essawi, M.K. (2017). "Investigation of Reinforcing Modified Asphalt Concrete Mixtures by Different Geogrid Types", M.Sc. Thesis, Department of Civil Engineering, University of Babylon, Iraq

[3] Al-Recaby, M.K.M. (2016). "Dynamic Response of Pile Group Model in Sandy Soil to Lateral Excitation", Ph.D. Thesis, Department of Civil
Engineering, University of Technology, Baghdad, Iraq.

[4] Al-Tameemi, S.M.K. (2018). "Experimental and Numerical Study on the Effect of Liquefaction Potential of Piles in Sandy Layered Soil under Earthquake Loading", Ph.D. Thesis, Department of Civil Engineering, Al-Nahrain University, Baghdad, Iraq.

[5] El-Emam, M.M. and Bathurst, R.J. (2004). "Experimental Design, Instrumentation and Interpretation of Reinforced Soil Wall Response Using a Shaking Table", UPMG-International Journal of Physical Modelling in Geotechnics, Vol.4, No.4, Canada.

[6] Fakhraldin, M.K. (2016). "Improvement of Loose Granular Soil by Using Geogrid Reinforcement", Kufa Journal of Engineering, Vol. 7, No. 3, October 2016, P.P.66-79.

[7] Meymand,P.J. Lok, T.M., Pestana, J.M., Riemer, M.F. and Seed, R.B. (1999). "Large-Scale Shaking Table Model Tests and Analyses of Seismic SoilPile Superstructure Interaction", Proc. 2nd ICEGE, 1, pp341-352, Cited by Romo M.P. (2000).

[8] Salem, L.A. (2016). "The Effect of Interaction on Pile Raft System Settlement Subjected to Earthquake Excitation", Ph.D. Thesis, Department of Civil Engineering, Baghdad University, Baghdad, Iraq.

[9] Sa'ur, R.H.M. (2016). "Seismic Behavior of A SoilPile System", ", M.Sc. Thesis, Department of Civil Engineering, Al-Nahrain University, Baghdad, Iraq.

[10] Taha, A.M. (2014). "Static and Seismic Performance of Geosynthetics-strengthened Pile Foundations", Ph.D. Thesis, Western Ontario University 